\title{
The Roles of EP4 Prostanoid Receptors in Cancer Malignancy Signaling
}

\author{
Hiromichi Fujino \\ Laboratory of Chemical Pharmacology, Graduate School of Pharmaceutical Sciences, \\ Chiba University; 1-8-1 Inohana, Chuo-ku, Chiba 260-8675, Japan.
}

Received October 27, 2015

\begin{abstract}
The lipid mediator prostanoids consist of prostaglandins and thromboxanes, and are synthesized from arachidonic acid by the action of cyclooxygenase. There are five major prostanoids, including prostaglandin $E_{2}\left(P_{G E}\right)$, and they are involved in a variety of biological responses such as inflammation, allergy, parturition, and tumorigenesis. These prostanoids exert their effects via activation of their cognate $G$ protein coupled receptors, e.g., E-type prostanoid (EP) receptors for PGE $_{2}$. The EP receptors are composed of four subtypes, namely EP1 to EP4. Here, breakthroughs in the last dozen years of research are introduced, with a special focus on some important findings of EP4 receptor-mediated signaling and the signaling associated with cancer development, particularly in colon cancer.
\end{abstract}

Key words E-type prostanoid (EP) 4 receptor; prostaglandin $\mathrm{E}_{2}\left(\mathrm{PGE}_{2}\right) ; \mathrm{G}_{\mathrm{i}}$-protein; phosphatidylinositol 3 (PI3) kinase; cyclooxygenase-2 (COX-2); colon cancer malignancy cycle

\section{INTRODUCTION}

When the second cAMP produced E-type prostanoid (EP) receptors were cloned in 1994, the beginning of the confusion started. ${ }^{1)}$ Until that time point, the subfamily of EP receptors had been pharmacologically defined, and was composed of only three subtypes, namely putative $\mathrm{G}_{\mathrm{q}}$-coupled EP1 receptors, $\mathrm{G}_{\mathrm{s}}$-coupled EP2 receptors and $\mathrm{G}_{\mathrm{i}}$-coupled EP3 receptors. $^{2,3)}$ Thus, in 1992, the first cloned EP receptors were found to inhibit cAMP formation so that they were considered as EP3 receptors in mouse ${ }^{4)}\left(1994\right.$ in human $\left.{ }^{3)}\right)$. In 1993, the second and the third EP receptors were then cloned and were found to increase phosphoinositide hydrolysis and stimulate cAMP formation, respectively, in mouse and in human. ${ }^{5-9)}$ Therefore, they were defined as EP1 and EP2 receptors. A year later, the newly cloned second cAMP produced human $\mathrm{EP}$ receptors, i.e., the fourth $\mathrm{EP}$ receptors, which were also found to stimulate cAMP formation in humans. ${ }^{10)}$ Intriguingly, the newly cloned receptors were sensitive to the pharmacological EP2 receptor agonist butaprost, whereas the first receptors were not. ${ }^{10)}$ Consequently, the butaprost-sensitive, the new, and the fourth EP receptors were designated as EP2 receptors, whereas the prior-cloned butaprost-insensitive EP2 receptors were then renamed as EP4 receptors. ${ }^{1,2,10-12)}$

Although it was revealed that there are two subtypes of $\mathrm{G}_{\mathrm{s}}$-protein coupled EP receptors, EP2 and EP4 receptors, significant differences were not found in terms of the second messenger signaling of these receptors. Interesting twists for significant differences were then found with respect to the agonist-induced desensitization in 1996 and internalization in 2000 of both receptors. ${ }^{13,14)}$ Thus, EP4 receptors, but not EP2 receptors, were found to undergo prostaglandin $\mathrm{E}_{2}\left(\mathrm{PGE}_{2}\right)-$ induced desensitization, ${ }^{13)}$ as well as internalization ${ }^{14)}$ (Fig. 1A). Incidentally, a notable structural difference between EP2 and EP4 receptors has been found in their carboxyl tails since their cloning. Thus, in human EP4 receptors, they consist of 148 amino acids, whereas in human EP2 receptors, they have 40 amino acids. ${ }^{1)}$ Accordingly, the EP4 receptor-mediated
$\mathrm{PGE}_{2}$-induced desensitization and internalization as well as sequestration and phosphorylation are believed to be triggered by the longer intracellular carboxyl tail of the EP4 receptors. $^{14-16)}$ Interestingly, two protein kinase A (PKA) consensus phosphorylation sites, serine 222 and serine 259, were existed in the third intracellular loop (ICL3) of EP4 receptors, however, the deletion of this region did not affect $\mathrm{PGE}_{2}$-induced desensitization and internalization. ${ }^{16)}$ Moreover, the same study also concluded that the agonist-mediated phosphorylation of ICL3 in EP4 receptors was not significant. ${ }^{16)}$ Therefore, agonist-mediated desensitization as well as internalization have been suggested as PKA-mediated phosphorylation-independent events in EP4 receptor activation. ${ }^{16)}$

\section{BRIEF SKETCH OF FINDINGS FROM STUDIES USING HEK CELL MODEL SYSTEM}

Intriguingly, when using HEK-293 cells stably expressing either EP2 receptors or EP4 receptors as a model system, it appeared that $\mathrm{PGE}_{2}$-stimulated total cAMP formation was less in cells expressing the EP4 receptors compared to those expressing the EP2 receptors. ${ }^{17-19)}$ Although they were mouse and human receptors, this differential ability to produce cAMP by these receptors was also shown in COS cells transiently expressing these receptors, ${ }^{7,10)}$ suggesting the reflection of internalization followed by desensitization of the EP4 receptors at that moment. Moreover, based on the cAMP assay as well as radioligand binding assay, the affinity for $\mathrm{PGE}_{2}$ was approximately one order greater in EP4 receptors as compared to the EP2 receptors, ${ }^{19)}$ so the above differences were not a simple reflection of the affinity of those receptors for $\mathrm{PGE}_{2}$.

The significance of the differences in EP2 and EP4 receptors in terms of signal transduction pathways emerged when the receptors were linked to the pathway involving $\beta$-catenin/T-cell factor (Tcf)-mediated signaling. ${ }^{17)}$ This relation was inspired by the findings in 2000 that PKA can phosphorylate and inactivate glycogen synthase kinase-3 (GSK3), ${ }^{20,21)}$ which is reported to phosphorylate $\beta$-catenin and 
the phosphorylated $\beta$-catenin is degraded via an ubiquitinmediated pathway. ${ }^{22}$ Therefore, inactivation of GSK3 would let the $\beta$-catenin translocate to the nucleus and alter the gene expression by interaction with the Tcf family of transcriptional factors. ${ }^{22)}$ Thus, using the Tcf responsive luciferase reporter gene, the $\beta$-catenin/Tcf-mediated signaling pathways were found with the stimulation of either EP2 or EP4 receptorexpressing HEK cells by $\mathrm{PGE}_{2}{ }^{17)}$ However, very interestingly, Tcf reporter activity was regulated differently between EP2 and EP4 receptor-mediated pathways ${ }^{17)}$; in EP2 receptor activation, it was primarily via a PKA-mediated pathway, whereas in EP4 receptors activation, it was primarily via a phosphatidylinositol 3-kinase (PI3K)-dependent pathway. ${ }^{17)}$ The following year, it was found that the additional PI3K-dependent pathway in EP4 receptor signaling led to the induction of the functional expression of early growth response factor 1 (EGR-1) following the phosphorylation of extracellular signalregulated kinases (ERKs). ${ }^{23)}$ Since EGR-1 was shown to upregulate membrane-associated $\mathrm{PGE}_{2}$ synthase, ${ }^{23)}$ a potential of positive feedback loop by EP4 receptor activation has been suggested, because the product of $\mathrm{PGE}_{2}$ synthase is obviously $\mathrm{PGE}_{2}$ itself. ${ }^{1,23,24)}$

A subsequent study has revealed that EP4 receptor-stimulated phosphorylation of ERKs and induction of EGR-1 can be inhibited by pretreatment with pertussis toxin (PTX), which blocks the ability of $\mathrm{G}_{\mathrm{i}}$-protein to inhibit the activity of adenylyl cyclase by transferral of ADP-ribose. ${ }^{19)}$ It was further confirmed by cAMP assay that pretreatment with PTX in HEK cells stably expressing EP4 receptors resulted in a significant increase in maximal $\mathrm{PGE}_{2}$-induced cAMP formation, but PTX essentially had no effect on $\mathrm{PGE}_{2}$-stimulated HEK cells stably expressing EP2 receptors as well as un-transfected parental HEK cells. ${ }^{19)}$ From these series of experiments, an additional PI3K-dependent pathway via EP4 receptor activation was discovered and found to originate from additional coupling to $\mathrm{G}_{\mathrm{i}}$-protein of EP4 receptors. ${ }^{19)}$

Although pretreatment with PTX of the EP4 receptor expressing $\mathrm{HEK}$ cells enhanced $\mathrm{PGE}_{2}$-stimulated cAMP formation, the ability to stimulate maximal cAMP formation was still lower, approximately a half to one third, compared to EP2 receptors, ${ }^{19)}$ and even the $\mathrm{EC}_{50}$ for $\mathrm{PGE}_{2}$-stimulated cAMP formation in EP4 receptor activation was one order lower than that of EP2 receptors as described earlier. ${ }^{19)}$ Indeed, the $\mathrm{PGE}_{2}$ stimulated PKA activity was approximately 3 to 4 times greater in EP2 receptor stimulation than in EP4 receptor stimulation by $\mathrm{PGE}_{2} \cdot{ }^{18)}$ Therefore, the differential abilities to produce cAMP by these receptors were found to be not just a reflection of internalization followed by desensitization of the EP4 receptors. More interestingly, in pretreatment with wortmannin, a PI3K inhibitor, the enhanced $\mathrm{PGE}_{2}$-stimulated PKA activity in EP4 receptor expressing HEK cells suggested that PKA activity is negatively regulated by the PI3K-mediated pathway, ${ }^{18)}$ which may be a similar regulatory mechanism to that reported in $\beta 2$-adrenergic receptors. ${ }^{25)}$ In addition, the phosphorylation of cAMP response element-binding protein (CREB) on serine 133, which is central to the regulation of CREB-mediated transcriptional activation, was evoked by the activation of both the EP2 and EP4 receptors. ${ }^{18)}$ However, similar to $\beta$-catenin/Tcf transcriptional activation, the regulation of CREB phosphorylation was primarily via activation of PKA in EP2 receptor expressing HEK cells, whereas it was primarily via activation of PI3K in EP4 receptor expressing HEK cells. ${ }^{17,18)}$

Based on the genome sequences reported previously, the EP4 receptors are located a little off from a branch of EP2, DP and IP receptor groups by phylogenic analysis. ${ }^{1,26)}$ Thus, in agreement with our findings from the HEK cell model system mentioned above, it appears that the EP2 and EP4 receptors do not share as much of their signal transduction pathways as initially predicted. That is to say, the EP4 receptors have an additional signaling pathway involving an alliance of $\mathrm{G}_{\mathrm{i}}$-protein/ PI3K/ERKs activations, i.e., the possibility to have additional functions, which may not be present in their old counterparts, the EP2 receptors (Fig. 1B).

In 1998, Dr. Hiromichi Fujino joined Dr. John W. Regan's laboratory in the College of Pharmacy, The University of Arizona as a Research Associate, after obtaining his Ph.D. at Dr. Yasuyuki Nomura's laboratory in the Faculty of Pharmaceutical Sciences, Hokkaido University in 1997. Since then his major research interests have been identification of molecular signaling pathways induced by various prostaglandins such as prostaglandin $E_{2}$ and prostaglandin $F_{2 \alpha}$. He has been responsible to some extent for the discovery and characterization of several novel signaling pathways involving the EP and FP prostanoid receptors. He was promoted to Assistant Research Scientist in 2001, and then to Associate Research Scientist in 2004. During his time in the United States, he received two competitive travel awards from scientific societies, and in 2003, he received a Post Doctoral Scientist Award from the Division of Molecular Pharmacology of the American Society for Pharmacology and Experimental Therapeutics (ASPET).

In 2005, he moved back to Japan to work in Dr. Toshihiko Murayama's laboratory at Chiba University as a Lecturer, then Associate Professor in 2006 until the present. His current main research is working on the role of EP4 receptors in cancer in order to understand how and why EP4 receptors are implicated in malignancies, especially in the early stages of colon cancer development. After a decade of research of prostanoid receptor signaling associated with cancer development, particularly in colon cancer, he received The Pharmaceutical Society of Japan Award for Divisional Scientific Promotions (4B; Pharmacology) in 2015. In October, 2015 his group received the Young Investigator's Award with respect to the roles of carboxyl-terminal tail of EP4 receptors from the Kanto Division of the Japanese Pharmacological Society. 


\section{A}
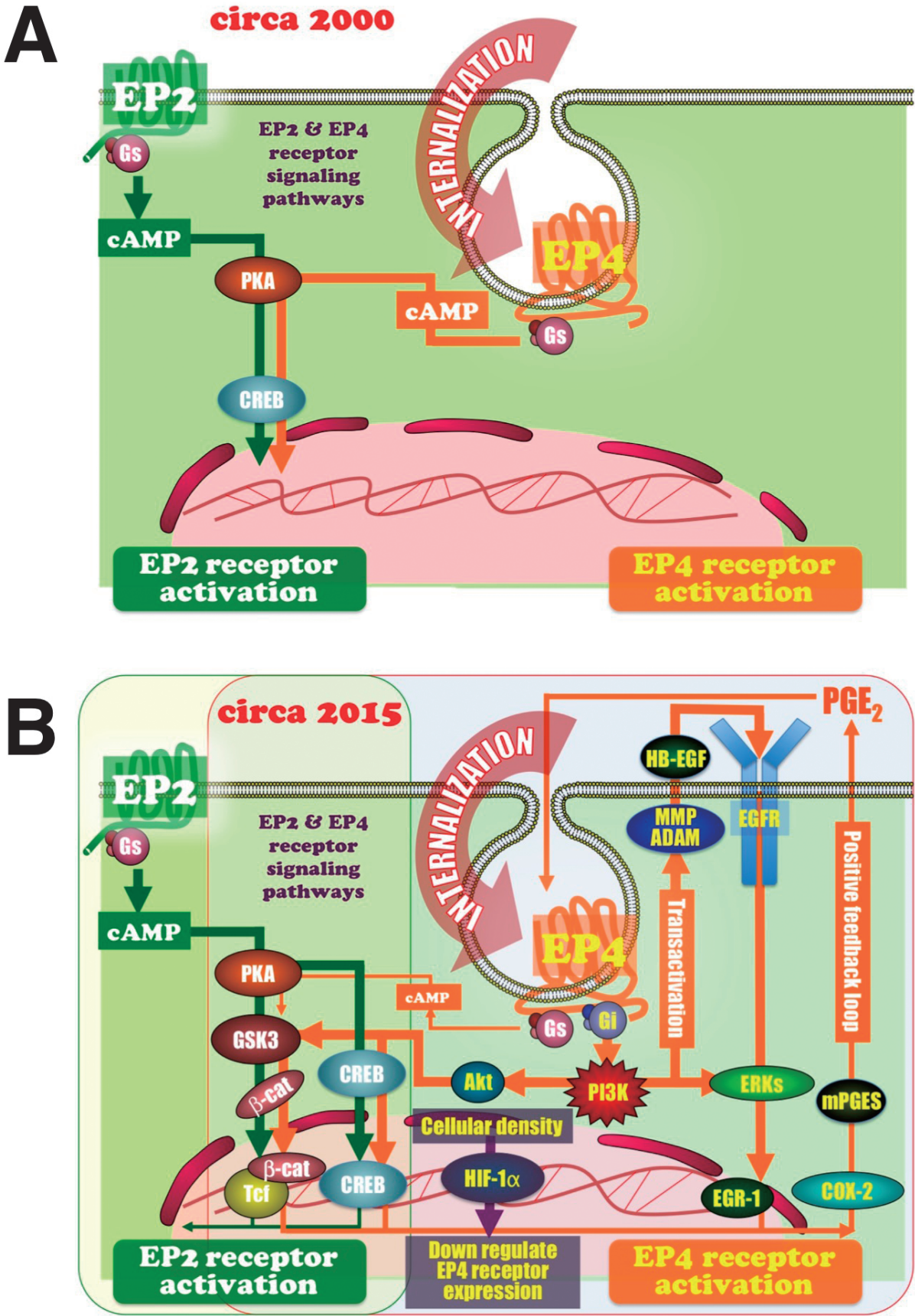

Fig. 1. EP2 and EP4 Receptor Signaling Pathways: Circa 2000 (A), Circa 2015 (B)

A. Both EP2 and EP4 receptors activate protein kinase A (PKA) via increased intracellular cyclic AMP (cAMP) formation followed by phosphorylation of cAMP response element binding protein (CREB) through the activation of the $\mathrm{G}_{\mathrm{s}}$-protein-mediated pathway. This activation results in the internalization and desensitization of the EP4 receptors, which does not occur in EP2 receptors. B. Both EP2 and EP4 receptors stimulate $\beta$-catenin ( $\beta$-cat)/T-cell factor (Tcf) transcriptional activation to a similar degree through the inactivation of glycogen synthase kinase-3 (GSK3) by phosphorylation. However, EP ${ }_{2}$ receptors phosphorylate GSK3 and activate this pathway primarily through a PKA-dependent way, whereas EP4 receptors primarily activate a phosphatidylinositol 3-kinase (PI3K)- and protein kinase B (Akt)-dependent pathway. Additionally, EP4 receptors, but not EP2 receptors, stimulate the phosphorylation of the extracellular signal-regulated kinases (ERKs) and induce the functional expression of early growth response factor 1 (EGR-1) through a PI3K-dependent pathway. EGR-1 has been shown to regulate the expression of membrane-associated PGE 2 synthase (mPGES) via activation of the $\mathrm{G}_{\mathrm{i}}$-protein-mediated pathway. Moreover, in collaboration with the PI3K-mediated, PKA-independent activation of CREB, the $\mathrm{G}_{\mathrm{i}}$-proteinmediated signaling pathway induces COX-2 expression via transactivation of the epidermal growth factor (EGF) receptor (EGFR) following an PI3K-mediated extracellular pathway involving sequential activation of matrix metalloproteinase (MMP)/a disintegrin and metalloproteinase (ADAM), induction of heparin binding-EGF-like growth factor (HB-EGF). EP4 receptor-mediated induction of COX-2 is able to set up a positive feedback loop by increasing COX-2 expression and increasing prostanoid biosynthesis such as prostaglandin $\mathrm{E}_{2}\left(\mathrm{PGE}_{2}\right)$. Furthermore, the induction of hypoxia inducible factor-1 $\alpha(\mathrm{HIF}-1 \alpha)$ increases in a cellular density-dependent manner, which down regulates the expression of EP4 receptors followed by EP4 receptor-mediated COX-2 induction.

\section{BRIEF SKETCH OF FINDINGS USING HCA-7 COLON CANCER CELL SYSTEM}

It is widely accepted that increases in the expression of cyclooxygenase-2 (COX-2) and its product $\mathrm{PGE}_{2}$ are hallmarks of colon cancer. ${ }^{27,28)}$ Indeed, knockout mouse studies have suggested that all subtypes of EP receptors are implicated in the pathophysiology of colon cancer to some extent. ${ }^{27)}$ However, among the subtypes, the $\mathrm{G}_{\mathrm{s}}$-protein coupled EP2 and/ or EP4 receptors may be involved in tumorigenic mechanisms, ${ }^{1,24,29,30)}$ since one of the key factors to regulate the induction of COX-2 is known to be the cAMP-response de- 
pendent activation of CREB. ${ }^{31,32)}$ Because the functional and signaling differences between EP2 and EP4 receptors were not fully appreciated at that time, the receptor subtypes that were principally responsible were not really identified. However, these implications were underpinned by the results described above; the activation of $\beta$-catenin/Tcf signaling, a key signal for colon cancer development, and the activation of CREBs have been shown to be regulated by both EP2 and/or EP4 receptors $^{17,18)}$ (Fig. 1B).

Meanwhile, from the aspect of the receptor distributions in human colon, EP2 receptors are reported to be expressed at the apex of the colonic mucosa. ${ }^{33)}$ In contrast, EP4 receptors are strongly expressed in the lateral crypt epithelia, ${ }^{33)}$ where cellular differentiation and migration take place so that dysregulation of these processes could facilitate tumor formation. ${ }^{34)}$ Of particular interest, the expression of EP4 receptors is reported to be increased during colorectal cancer progression. ${ }^{35)}$ These increments of EP4 receptors were also reported in lung carcinoma cells ${ }^{36)}$ and in cervical cancer cells. ${ }^{37)}$

In addition to the elevated levels of expression of the receptors during carcinogenesis, increased activity of PI3Kmediated functions is also one of the major features of colon cancer. ${ }^{24,38)}$ Thus, it has been shown that in colon cancer cells, the PI3K-mediated EP4 receptor-signaling pathway increased cell motility and proliferation. ${ }^{39)}$ According to the results obtained in HEK model system as described above, ${ }^{17-19,23)}$ EP4 receptors appear to play functional roles in colon cancer malignancy. Thus, the detailed mechanisms and pathophysiological roles of these signaling pathways have been explored using the human colon cancer HCA-7 cell line since the cells were found to express mRNAs encoding EP2, EP3 and EP4 receptor subtypes. ${ }^{40)}$ Moreover, even though a number of human colorectal adenocarcinoma cell lines lost the polarity of their tissue of origin, $\mathrm{HCA}-7$ cells have been reported to retain some of the functional features of normal colonic epithelial. ${ }^{41)}$ Thus, HCA-7 cells are highly advantageous in that they may be one of the most appropriate cells to evaluate the early development stages of colon carcinogenesis.

Again, increased expression of COX-2 induced by $\mathrm{PGE}_{2}$ will obviously have potential as a positive feedback loop since one of the products of COX-2 is $\mathrm{PGE}_{2}$ itself. ${ }^{1,23,24)}$ Moreover, activation of CREB is known to be one of the key factors that regulates the induction of COX-2 so that both EP2 and EP4 receptors are believed to be involved in tumorigenic mechanisms. Therefore, specific EP receptor subtypes as well as the responsible signaling pathways in colon cancer cells have remained unclear. Thus, the advantage to using HCA-7 cells as above is that the cells express both EP2 and EP4 receptor mRNAs.

The ability of EP4 receptors to induce COX-2 expression in HCA-7 cells was first proved by experiments that showed $\mathrm{PGE}_{2}$-induced COX-2 expression was abrogated by pretreatment with the EP4 receptor antagonist GW627368X. ${ }^{42)}$ Moreover, the EP3/EP4 receptor agonist prostaglandin $\mathrm{E}_{1}$-alcohol induced COX-2 expression in HCA-7 cells. In contrast, COX-2 was not induced in HCA-7 cells by the EP2 or EP3 receptor agonists butaprost or sulprostone, respectively. ${ }^{42}$ )

Of particular importance, the induction of COX-2 by $\mathrm{PGE}_{2}$-activated EP4 receptors in $\mathrm{HCA}-7$ cells is primarily mediated by coupling of the receptor to $G_{i}$-protein followed by the activation of PI3K and ERKs, which is consistent with the findings from the HEK cell model system as noted above.
The pathway was also shown to involve the transactivation of epidermal growth factor (EGF) receptors following the induction of metalloproteinase activity and the production of the EGF receptor ligand heparin-binding EGF-like growth factor $^{42)}$ (Fig. 1B). Intriguingly, it has also been found that the EP4 receptor/ $\mathrm{G}_{\mathrm{i}}$-protein/PI3K-induced COX-2 pathway is not completely linear and another signaling pathway, a cAMP/ PKA line to CREB activation, ${ }^{42)}$ may also be involved, as previously reported (Fig. 1B).

A recent subsequent study showed that cellular densitydependent induction of hypoxia inducible factor-1 $\alpha$ (HIF-1 $\alpha$ ) protein expression was responsible for and accompanied by the reduction of expression of EP4 receptors, and resulted in the reduction of EP4 receptor-mediated $\mathrm{PGE}_{2}$-induced $\mathrm{COX}-2$ expression in HCA-7 cells. ${ }^{43}$ ) Thus, $\mathrm{PGE}_{2}$ has the potent ability to induce expression of COX-2 as described above via EP4 receptor activation at a low cellular density of HCA-7 cells. However, the induction of COX-2 by $\mathrm{PGE}_{2}$ stimulation was significantly decreased with a clear inverse correlation to significant induction of HIF-1 $\alpha$ expression under a high cellular density of HCA-7 cells. ${ }^{43}$ Therefore, the EP4 receptormediated cellular responses were suggested to be regulated by cellular density dependent changes in the expression of HIF-1 $\alpha^{43}$ (Fig. 1B). The significance of the finding is that different levels of EP4 receptor expression would cause the cancer cells to respond to $\mathrm{PGE}_{2}$ differently, and/or the cancer cells to determine the fate/stage depending on the surrounding environment, ${ }^{43)}$ e.g. the numbers of surrounding cells. Whereas interestingly, the translational activation of EP2 and/or EP3 receptors was not altered so that the expressions of EP2 as well as EP3 receptors may not be changed by cellular density and/or HIF-1 $\alpha$ protein expression levels. ${ }^{43}$

However, a simple skepticism has then arisen in regard to the results described above. Thus, if EP4 receptors are really involved in colon cancer malignancy, why do these receptors decrease their expression in association with an increase in the cancer cell population to a high cellular density? Meanwhile, the induction of COX-2 expression was previously reported to be detected from a very early growth stage of a carcinoma. ${ }^{44)}$ It is also well-recognized that augmentation of HIF- $1 \alpha$ is correlated with malignant progression of cancer such as angiogenesis by inducing the expression of vascular endothelial growth factor (VEGF) for providing nutrients to rapidly growing cancer cells, ${ }^{45)}$ and migration/metastasis by HIF-1 $\alpha$-induced VEGF activating to high affinity ligand binding VEGF receptor-1.46) As we have shown previously, the stimulation of EP3 receptors induced VEGF receptor-1 expression followed by enhancing the cellular migration, $\left.{ }^{46}\right)$ plausibly evoked via VEGF induced by increased HIF- $1 \alpha$ in HCA-7 cells cultured at high cellular density. ${ }^{43)}$ Thus, upon proliferation of the cells via the positive feedback loop of EP4 receptors $/ \mathrm{COX}-2 / \mathrm{PGE}_{2}$, the increment in HIF- $1 \alpha$ is proceeding concomitantly. When the density of the cells reaches the point where EP4 receptors have lost their function(s) by reduction of their expression, slightly-synthesized and/or remaining $\mathrm{PGE}_{2}$ may act on the stationary EP3 receptors, whose expression was shown to be unaltered by cell density, and induces VEGF receptor-1 expression in association with increased HIF- $1 \alpha$ induced VEGF followed by stimulation of cellular migration such as invasion and/or metastasis. ${ }^{39,45,46)}$ Importantly, EP3 receptors have been shown to have one of the highest affini- 


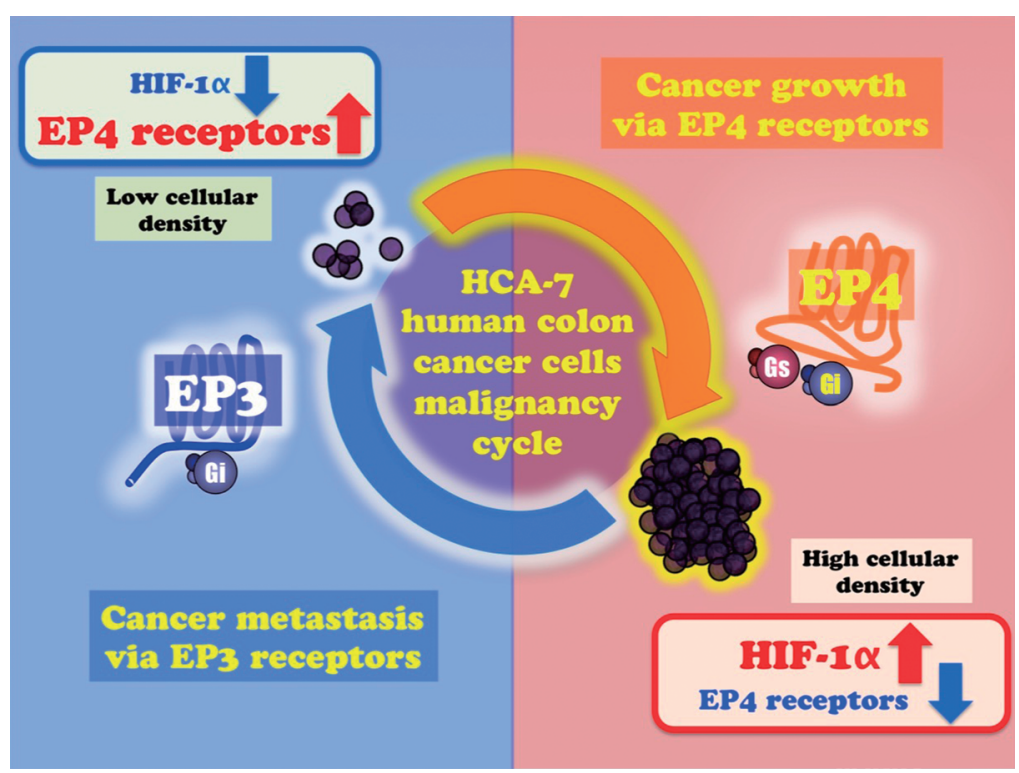

Fig. 2. HCA-7 Human Colon Cancer Cell Malignancy Cycle by EP4 and EP3 Receptors

Reduction of the EP4 receptors by induction of HIF-1 $\alpha$ at a high cellular density would decrease COX-2 levels and promote colon cancer cells from the cancer growth stage to the metastatic stage by switching the responsive primary EP receptor subtypes from EP4 receptors to EP3 receptors. After the migration, the cells will re-induce the EP4 receptors following the reduction of HIF-1 $\alpha$ expression at low cellular density, which would increase COX-2 induction again and progress colon cancer cells from the metastatic stage to the cancer growth stage by switching back the responsive receptors to EP4 receptors.

ties for $\mathrm{PGE}_{2}{ }^{2,47)}$ so that EP3 receptors are likely to be able to induce cellular migration at even the low levels of $\mathrm{PGE}_{2}$ produced by the reduced expressions of COX-2 following decline of the EP4 receptors.

Obviously, in the tissue(s)/organ(s) of the body where the migrated cells remain and settle, the cellular density will return to the lower levels so that the expression of HIF-1 $\alpha$ will decrease. Subsequently, the decline in expression of HIF-1 $\alpha$ will induce the re-appearance of the EP4 receptors as well as the induction of COX-2 if the $\mathrm{PGE}_{2}$ is provided by themselves and/or from somewhere else, since as described above, EP4 receptors are another high affinity receptor for $\mathrm{PGE}_{2}{ }^{2,47)}$

Taken all together, a reduction of the EP4 receptors by induction of HIF-1 $\alpha$ at high cellular density would decrease COX-2 levels and promote colon cancer cells from the cancer growth stage to the metastatic stage by switching the responsive primary EP receptor subtypes from EP4 receptors to EP3 receptors. After the migration, the cells will then turn around; re-induction of EP4 receptors following the reduction of HIF-1 $\alpha$ expression at low cellular density, which would increase COX-2 induction again and promote colon cancer cells from the metastatic stage to the cancer growth stage by switching back the responsive receptors to EP4 receptors; i.e., a complete cycle of the colon cancer cell malignancy as shown in Fig. 2.

Finally, more recently, we have revealed the important roles of the $\mathrm{G}_{\mathrm{s}}$-protein/cAMP/PKA alliance on de novo synthesis of $\mathrm{PGE}_{2}$ in HCA-7 cells. ${ }^{48)}$ Thus, the activation of EP4 receptors by $\mathrm{PGE}_{2}$ in $\mathrm{HCA}-7$ cells evoked PKA-dependent re-activation of ERKs, which led to prolonged de novo synthesis of $\mathrm{PGE}_{2}$ plausibly via a mechanism of resensitization involving the poly-alanine residues (five alanines), which are embedded between two PKA consensus phosphorylation sites, serine 222 and serine 259 , as described above, ${ }^{48}$ of the ICL3 region of EP4 receptors. ${ }^{49)}$

Meanwhile, direct activation of EGF receptors by EGF also induced similar amounts of COX-2 in this cell line. ${ }^{48)}$ There- fore, the effects of EGF-stimulated EGF receptors in HCA-7 cells was also examined and it was found that EGF stimulation also induced COX-2 and de novo synthesis of $\mathrm{PGE}_{2}$. However, activation of this pathway was transient and not mediated by PKA. ${ }^{48)}$

As described earlier, HCA-7 cells are possibly the most appropriate cells with which to evaluate the early development stage of colon carcinogenesis, since the cells retain some of the functional features of normal colonic epithelia. ${ }^{41)}$ Thus, the novel biphasic activation of ERKs followed by prolonged de novo $\mathrm{PGE}_{2}$ synthesis mediated by PKA activation in EP4 receptor-stimulated signaling provides an insight into the importance of the $\mathrm{G}_{\mathrm{s}}$-protein/cAMP/PKA pathway in cancer development and why not EGF but $\mathrm{PGE}_{2}$ has been linked to an early stage of carcinogenesis, especially in EP4 receptorinduced development of colon cancer.

\section{CONCLUSION}

The combination roles of induction of COX-2 by the $\mathrm{G}_{\mathrm{i}}$-protein-mediated pathway of EP4 receptors and amplifying and/or prolonging the de novo synthesis of $\mathrm{PGE}_{2}$ by the $\mathrm{G}_{\mathrm{s}}$-proteinmediated pathway, will be key in the future of the receptors, which have profound significances to understand how and why EP4 receptors are implicated in the malignancies, especially the early stages of colon cancer development.

Acknowledgments I would like to acknowledge Dr. Toshihiko Murayama and his past and current laboratory members at Chiba University as well as Dr. John W. Regan and his past and present colleagues at The University of Arizona for their valuable contributions to this work.

Conflict of Interest The author declares no conflict of interest. 


\section{REFERENCES}

1) Regan JW. EP2 and EP4 prostanoid receptor signaling. Life Sci., 74, 143-153 (2003)

2) Narumiya S, Sugimoto $Y$, Ushikubi F. Prostanoid receptors: structures, properties, and functions. Physiol. Rev., 79, 1193-1226 (1999).

3) Regan JW, Bailey TJ, Donello JE, Pierce KL, Pepperl DJ, Zhang D, Kedzie KM, Fairbairn CE, Bogardus AM, Woodward DF, Gil DW. Molecular cloning and expression of human EP3 receptors: evidence of three variants with differing carboxy termini. Br. J. Pharmacol., 112, 377-385 (1994).

4) Sugimoto Y, Namba T, Honda A, Hayashi Y, Negishi M, Ichikawa A, Narumiya S. Cloning and expression of a cDNA for mouse prostaglandin E receptor EP3 subtype. J. Biol. Chem., 267, 6463-6466 (1992).

5) Watabe A, Sugimoto Y, Honda A, Irie A, Namba T, Negishi M, Ito S, Narumiya S, Ichikawa A. Cloning and expression of cDNA for a mouse EP1 subtype of prostaglandin E receptor. J. Biol. Chem., 268, 20175-20178 (1993)

6) Funk CD, Furci L, FitzGerald GA, Grygorczyk R, Rochette C, Bayne MA, Abramovitz M, Adam M, Metters KM. Cloning and expression of a cDNA for the human prostaglandin E receptor EP1 subtype. J. Biol. Chem., 268, 26767-26772 (1993).

7) Honda A, Sugimoto $Y$, Namba $T$, Watabe A, Irie A, Negishi M, Narumiya S, Ichikawa A. Cloning and expression of a cDNA for mouse prostaglandin E receptor EP2 subtype. J. Biol. Chem., 268, 7759-7762 (1993).

8) An S, Yang J, Xia M, Goetzl EJ. Cloning and expression of the EP2 subtype of human receptors for prostaglandin $\mathrm{E}_{2}$. Biochem. Biophys. Res. Commun., 197, 263-270 (1993).

9) Bastien L, Sawyer N, Grygorczyk R, Metters KM, Adam M. Cloning, functional expression, and characterization of the human prostaglandin $\mathrm{E}_{2}$ receptor EP2 subtype. J. Biol. Chem., 269, 1187311877 (1994).

10) Regan JW, Bailey TJ, Pepperl DJ, Pierce KL, Bogardus AM, Donello JE, Fairbairn CE, Kedzie KM, Woodward DF, Gil DW. Cloning of a novel human prostaglandin receptor with characteristics of the pharmacologically defined EP2 subtype. Mol. Pharmacol., 46, 213-220 (1994).

11) Woodward DF, Jones RL, Narumiya S. International union of basic and clinical pharmacology. LXXXIII: classification of prostanoid receptors, updating 15 years of progress. Pharmacol. Rev., 63, 471-538 (2011).

12) Yokoyama U, Iwatsubo K, Umemura M, Fujita T, Ishikawa Y. The prostanoid EP4 receptor and its signaling pathway. Pharmacol. Rev., 65, 1010-1052 (2013).

13) Nishigaki N, Negishi $M$, Ichikawa A. Two $G_{\mathrm{s}}$-coupled prostaglandin E receptor subtypes, EP2 and EP4, differ in desensitization and sensitivity to the metabolic inactivation of the agonist. Mol. Pharmacol., 50, 1031-1037 (1996).

14) Desai S, April H, Nwaneshiudu C, Ashby B. Comparison of agonist-induced internalization of the human EP2 and EP4 prostaglandin receptors: role of the carboxyl terminus in EP4 receptor sequestration. Mol. Pharmacol., 58, 1279-1286 (2000).

15) Bastepe M, Ashby B. The long cytoplasmic carboxyl terminus of the prostaglandin $\mathrm{E}_{2}$ receptor EP4 subtype is essential for agonistinduced desensitization. Mol. Pharmacol., 51, 343-349 (1997).

16) Slipetz D, Buchanan S, Mackereth C, Brewer N, Pellow V, Hao C, Adam M, Abramovitz M, Metters KM. Sequestration and phosphorylation of the prostaglandin $\mathrm{E}_{2}$ EP4 receptor: dependence on C-terminal tail. Biochem. Pharmacol., 62, 997-1012 (2001).

17) Fujino H, West KA, Regan JW. Phosphorylation of glycogen synthase kinase-3 and stimulation of T-cell factor signaling following activation of EP2 and EP4 prostanoid receptors by prostaglandin $\mathrm{E}_{2}$. J. Biol. Chem., 277, 2614-2619 (2002).

18) Fujino H, Salvi S, Regan JW. Differential regulation of phosphory- lation of the cAMP response element-binding protein after activation of EP2 and EP4 prostanoid receptors by prostaglandin $\mathrm{E}_{2}$. Mol. Pharmacol., 68, 251-259 (2005).

19) Fujino H, Regan JW. EP4 prostanoid receptor coupling to a pertussis toxin-sensitive inhibitory G protein. Mol. Pharmacol., 69, 5-10 (2006).

20) Li M, Wang X, Meintzer MK, Laessig T, Birnbaum MJ, Heidenreich KA. Cyclic AMP promotes neuronal survival by phosphorylation of glycogen synthase kinase 3 $\beta$. Mol. Cell. Biol., 20, 9356-9363 (2000).

21) Fang X, Yu S, Lu Y, Bast RC Jr, Woodgett JR, Mills GB. Phosphorylation and inactivation of glycogen synthase kinase 3 by protein kinase A. Proc. Natl. Acad. Sci. U.S.A., 97, 11960-11965 (2000).

22) Cohen P, Frame S. The renaissance of GSK3. Nat. Rev. Mol. Cell Biol., 2, 769-776 (2001).

23) Fujino $\mathrm{H}, \mathrm{Xu} \mathrm{W}$, Regan JW. Prostaglandin $\mathrm{E}_{2}$ induced functional expression of early growth response factor-1 by EP4, but not EP2, prostanoid receptors via the phosphatidylinositol 3-kinase and extracellular signal-regulated kinases. J. Biol. Chem., 278, 1215112156 (2003)

24) Fujino H, Regan JW. Prostanoid receptors and phosphatidylinositol 3-kinase: a pathway to cancer? Trends Pharmacol. Sci., 24, 335-340 (2003).

25) Jo SH, Leblais V, Wang PH, Crow MT, Xiao RP. Phosphatidylinositol 3-kinase functionally compartmentalizes the concurrent $\mathrm{G}_{\mathrm{s}}$ signaling during $\beta 2$-adrenergic stimulation. Circ. Res., 91, 46-53 (2002).

26) Toh H, Ichikawa A, Narumiya S. Molecular evolution of receptors for eicosanoids. FEBS Lett., 361, 17-21 (1995).

27) Hull MA, Ko SC, Hawcroft G. prostaglandin EP receptors: targets for treatment and prevention of colorectal cancer? Mol. Cancer Ther., 3, 1031-1039 (2004).

28) Eisinger AL, Prescott SM, Jones DA, Stafforini DM. The role of cyclooxygenase-2 and prostaglandin in colon cancer. Prostaglandins Other Lipid Mediat., 82, 147-154 (2007).

29) Jabbour HN, Milne SA, Williams AR, Anderson RA, Boddy SC. Expression of COX-2 and PGE synthase and synthesis of $\mathrm{PGE}_{2}$ in endometrial adenocarcinoma: a possible autocrine/paracrine regulation of neoplastic cell function via EP2/EP4 receptors. Br. J. Cancer, 85, 1023-1031 (2001).

30) Dannenberg AJ, Lippman SM, Mann JR, Subbaramaiah K, DuBois RN. Cyclooxygenase-2 and epidermal growth factor receptor: pharmacologic target for chemoprevention. J. Clin. Oncol., 23, 254-266 (2005).

31) Bradbury DA, Newton R, Zhu YM, El-Haroun H, Corbett L, Knox AJ. Cyclooxygenase-2 induction by bradykinin in human pulmonary artery smooth muscle cells is mediated by the cyclic AMP response element through a novel autocrine loop involving endogenous prostaglandin $\mathrm{E}_{2}$, E-prostanoid 2 (EP2) and EP4 receptors. $J$. Biol. Chem., 278, 49954-49964 (2003).

32) Nishihara H, Hwang M, Kizaka-Kondoh S, Eckmann L, Insel PA. Cyclic AMP promotes cAMP-responsive element-binding proteindependent induction of cellular inhibitor of apoptosis protein-2 and suppresses apoptosis of colon cancer cells through ERK1/2 and p38 MAPK. J. Biol. Chem., 279, 26176-26183 (2004).

33) Takafuji V, Cosme R, Lublin D, Lynch K, Roche JK. Prostanoid receptors in intestinal epithelium: selective expression, function, and change with inflammation. Prostaglandins Leukot. Essent. Fatty Acids, 63, 223-235 (2000).

34) Goss KH, Groden J. Biology of the adenomatous polyposis coli tumor suppressor. J. Clin. Oncol., 18, 1967-1979 (2000).

35) Chell SD, Witherden IR, Dobson RR, Moorghen M, Herman AA, Qualtrough D, Williams AC, Paraskeva C. Increased EP4 receptor expression in colorectal cancer progression promotes cell growth and anchorage independence. Cancer Res., 66, 3106-3113 (2006). 36) Ritzenthaler JD, Roman J, Han S. PPAR $\gamma / \delta$ agonist increases the 
expression of $\mathrm{PGE}_{2}$ receptor subtype EP4 in human lung carcinoma cells. Methods Mol. Biol., 512, 309-323 (2009).

37) Fukuda EY, Lad SP, Mikolon DP, Iacobelli-Martinez M, Li E. Activation of lipid metabolism contributes to interleukin-8 production during Chlamydia trachomatis infection of cervical epithelial cells. Infect. Immun., 73, 4017-4024 (2005).

38) Zhang J, Roberts TM, Shivdasani RA. Targeting PI3K signaling as a therapeutic approach for colorectal cancer. Gastroenterology, 141, 50-61 (2011)

39) Sheng H, Shao J, Washington MK, DuBois RN. Prostaglandin $E_{2}$ increases growth and motility of colorectal carcinoma cells. J. Biol. Chem., 276, 18075-18081 (2001).

40) Fujino H, Toyomura K, Chen XB, Regan JW, Murayama T. Prostaglandin $\mathrm{E}_{2}$ regulates cellular migration via induction of vascular endothelial growth factor receptor-1 in HCA-7 human colon cancer cells. Biochem. Pharmacol., 81, 379-387 (2011).

41) Kirkland SC. Dome formation by a human colonic adenocarcinoma cell line (HCA-7). Cancer Res., 45, 3790-3795 (1985).

42) Yoshida K, Fujino H, Otake S, Seira N, Regan JW, Murayama T. Induction of cyclooxygenase-2 expression by prostaglandin $\mathrm{E}_{2}$ stimulation of the prostanoid EP4 receptor via coupling to $\mathrm{G}_{a \mathrm{i}}$ and transactivation of the epidermal growth factor receptor in HCA-7 human colon cancer cells. Eur. J. Pharmacol., 718, 408-417 (2013).

43) Otake S, Yoshida K, Seira N, Sanchez CM, Regan JW, Fujino H, Murayama T. Cellular density-dependent down-regulation of EP4 prostanoid receptors via the up-regulation of hypoxia-inducible factor-1 $\alpha$ in HCA-7 human colon cancer cells. Pharmacol. Res. Perspect., 3, e00083 (2015).

44) Fujita T, Matsui M, Takaku K, Uetake H, Ichikawa W, Taketo MM, Sugihara K. Size- and invasion-dependent increase in cyclooxygenase 2 levels in human colorectal carcinomas. Cancer Res., 58, 4823-4826 (1998).

45) Liao D, Johnson RS. Hypoxia: a key regulator of angiogenesis in cancer. Cancer Metastasis Rev., 26, 281-290 (2007).

46) Kanno S, Oda N, Abe M, Terai Y, Ito M, Shitara K, Tabayashi K, Shibuya M, Sato Y. Roles of two VEGF receptors, Flt-1 and KDR, in the signal transduction of VEGF effects in human vascular endothelial cells. Oncogene, 19, 2138-2146 (2000).

47) Breyer RM, Bagdassarian CK, Myers SA, Breyer MD. Prostanoid receptors: subtypes and signaling. Annu. Rev. Pharmacol. Toxicol., 41, 661-690 (2001)

48) Fujino H, Seira N, Kurata N, Araki Y, Nakamura H, Regan JW, Murayama T. Prostaglandin $\mathrm{E}_{2}$-stimulated prostanoid EP4 receptors induce prolonged de novo prostaglandin $\mathrm{E}_{2}$ synthesis through biphasic phosphorylation of extracellular signal-regulated kinases mediated by activation of protein kinase A in HCA-7 human colon cancer cells. Eur. J. Pharmacol., 768, 149-159 (2015).

49) Lavoie H, Debeane F, Trinh QD, Turcotte JF, Corbeil-Girard LP, Dicaire MJ, Saint-Denis A, Pagé M, Rouleau GA, Brais B. Polymorphism, shared functions and convergent evolution of genes with sequences coding for polyalanine domains. Hum. Mol. Genet., 12, 2967-2979 (2003). 